\title{
GECOBRIDGE: A concept of a smart eco- friendly integrated bridge utilizing geopolymer and graded concrete technology
}

\author{
M. Mirza Abdillah Pratama ${ }^{1, *}$, Yustika Dyah Pratiwi ${ }^{2}$ Miftah Aliyil 'Ilmi ${ }^{2}$ and Alifah \\ Mahardika $^{1}$ \\ ${ }^{1}$ Department of Civil Engineering, Faculty of Engineering, Universitas Negeri Malang, 65145 \\ Malang, Indonesia \\ ${ }^{2}$ Department of Vocational Education, Faculty of Engineering, Universitas Negeri Malang, 65145 \\ Malang, Indonesia
}

\begin{abstract}
The development of geopolymer concrete technology was initially inspired by environmental issues from the use of cement as one of the main constituents in concrete that contribute to the major greenhouse gas emissions on earth. The utilization of fly ash is expected to reduce cement in concrete so that the effects of environmental pollution can be minimised. Fly ash is a by-product of coal combustion available abundantly in hundreds of coal-fired power plant spread all over Indonesia which also could become a source of the environmental pollutant. The integration of graded concrete technology along with geopolymer concrete can create high-performance structural elements while still being cost efficient. Currently, research development related to geopolymer concrete and graded concrete is potentially applied to public infrastructures such as bridges that can support the economic activities of local people. The application of porous asphalt and an integrated drainage system make GECOBRIDGE become concepts of a smart, efficient, and environmentally friendly bridge, both in terms of construction, operation, and maintenance. GECOBRIDGE is expected to become a bridge that can conserve water through rain harvesting so that it can be utilized for the cultivation of a hydroponic farm in the upstream area.
\end{abstract}

\section{Introduction}

Bridge is a massive infrastructure that has an important role in connecting communities separated by land barriers such as rivers, lakes, or intersection. The existence of road and bridges provide benefits to the community from the economic, social, and political side. In economic point of view, the bridge increases the economic growth of the local community; to serve access of goods and services deliveries from areas connected by the infrastructure; to create transportation modes across the bridge; and to initiate new economic activities in the communities living around the bridge. In terms of social culture, bridges can facilitate

\footnotetext{
* Corresponding author: mirza.abdillah.ft@um.ac.id
} 
social interaction between communities; strengthen the bonds of community; and to nurture sense of tolerance of social culture between communities. In political and national defence, the existence of bridges can improve national defence and is a symbol of progress achievement of a country [1].

In this paper, authors intend to propose a concept of a smart bridge called GECOBRIDGE (Geopolymer-based Economical Bridge) that integrates technological novelty in the field of civil engineering on the pavement, drainage system, bridge slab, and girder to create an efficient structure in planning, construction, operation and maintenance. This bridge concept is expected to be an alternative to bridge design that prioritises environmental aspects because it reduces the amount of cement used in structural elements and conserves rainwater runoff through rain harvesting patterns.

\section{Innovative bridge designs}

In designing bridges, several aspects that need to be considered are strength and stiffness of structure, structural stability, level of serviceability, durability, ease of implementation, economical, and aesthetics. The dimensions of the elements and types of materials are taken into account in order to obtain a strong, efficient, and stable bridge structure. The structural serviceability level is concerned about comparing resulting deflection caused by the workload to the codes and is controlled to keep it within the allowable range. The structure of the bridge is designed with a 50-year lifetime [2].

In general, GECOBRIDGE is designed with a span of 30 meters and 7 meters in width. The type of bridge adopted on GECOBRIDGE is a truss bridge in which this type is more competitive in terms of implementation costs, provides high levels of occupational safety, is fabricated structure elements, and provides long lifetime. The type of bridge truss applied is Through Warren Truss and the bridge abutment applied is full wall type because the cliff height is more than 4 meters.

GECOBRIDGE is divided into several innovative structural elements such as porous asphalt pavement, parallel drainage channel integrated into bridge slab, and geopolymer graded concrete girder (Figure 1).

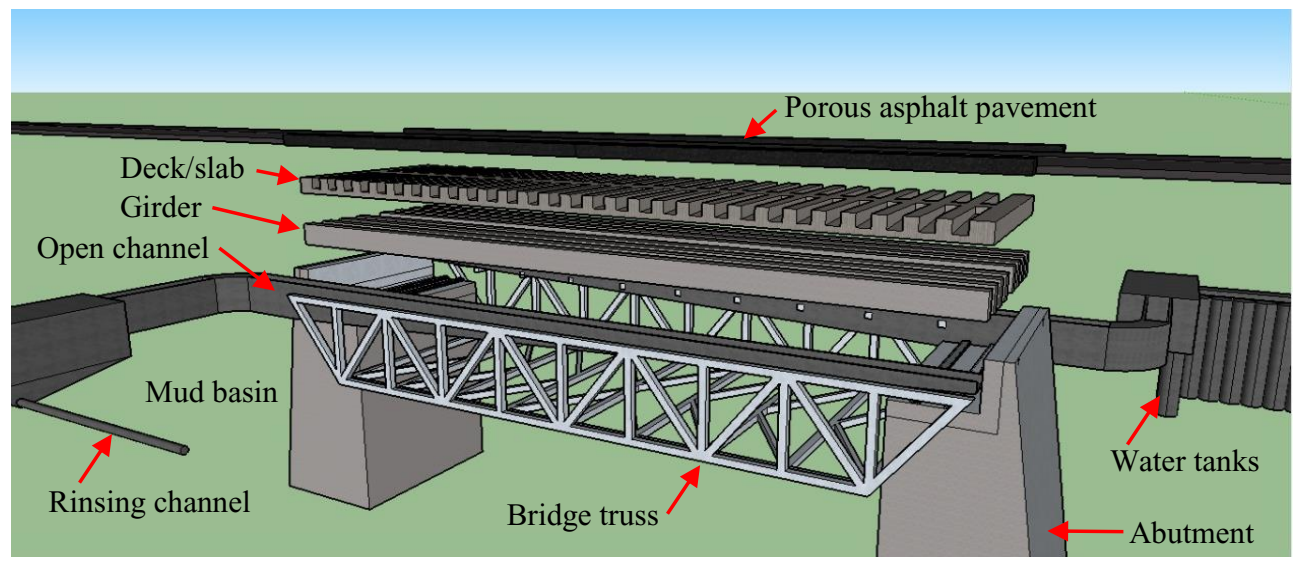

Fig. 1. Structural elements of GECOBRIDGE

\subsection{Porous asphalt pavement}


The type of road pavement applied to this bridge is flexible pavement which uses porous asphalt as its surfacing. The porous asphalt mixture uses a low proportion of fine aggregate to create large pores on the pavement. Porous asphalt has a gradation dominated by coarse aggregates reaching $85 \%$ of the total weight of the mixture. Despite its low stability, the addition of Gilsonite additives and natural fibres can increase asphalt adhesiveness [3, 4].

The cavities on the porous asphalt serve as water channels so that the rain falling on the pavement surface of the bridge will be absorbed and be channelled to the drainage channels underneath the pavement. The pavement cross-sectional slope is designed to be $2 \%$, aiming for water to easily runoff to the drainage system [5]. In addition, the porous asphalt is reliable in reducing noise resulting from transportation activities.

\subsection{Embedded parallel drainage system}

The drainage system in GECOBRIDGE is divided into two types: subsurface drainage and surface drainage. The subsurface drainage is embedded on the bridge deck, while the surface drainage is an open channel located on the side of the bridge. The rainwater absorbed through the porous asphalt pavement is then channelled through a net channel on the bridge deck to the open channel. The slope of the channel on the bridge deck is set at $2 \%$ so the water can flow easily. The water flowing through the net channels is then caught by an open channel designed with a 5\% slope toward the river's bank.

The flow of water from the open channel is herded into a mud basin so that the sediment transported by the water flow can be filtered maximumly. This mud basin is also equipped with a flushing channel located at the bottom so the sediment can be flushed through the rinsing channel to the river. The water that has been distilled from the mud basin is channelled to concrete water tanks with a depth of 6 meters using pipes. The water can be utilized further for the community, especially for the cultivation of hydroponic plants located on the side of the bridge. This scenario is one of rainwater harvesting methods to conserve water resources in areas. The idea of water conservation arises because the bridge is designed to be placed in the upstream areas where water discharge is fluctuating so water harvesting from upstream water discharge can be dangerous to residents $[6,7]$.

\subsection{Geopolymer-graded concrete girder}

Previous research has shown that fly ash could possibly replace cement as a binding material in concrete through geopolymerisation process. This procedure requires activator of sodium hydroxide 8-12 Molar to activate silica and alumina contained in fly ash. Fly ash used is class $\mathrm{F}$ for its high content of silica and alumina. Until now geopolymer fly ashbased concrete can achieve a compressive strength of $51.3 \mathrm{MPa}$ and can be classified as high strength concrete [8-12]. A series of laboratory tests are still being carried out to analyse the mechanical properties of geopolymer concrete, but so far geopolymer concrete is highly prospective to be applied to structural applications such as bridge girders and other bridge elements such as slab and abutment.

Until now, material optimisation use in structural elements has become the focus of construction implementation as it involves the construction costs allocated to a project. Reduction of the construction cost can be approached either by the applying of an effective construction method and choosing appropriate materials to the requirement. The application of geopolymer concrete technology can actually be categorised in the form of construction optimisation by diminishing cement in the concrete mix, but this optimisation can be maximised by applying concrete gradation technique in bridge girder.

A graded structure in concrete is obtained by combining two distinctly different concrete strength mixes and applying intensive compaction in order to obtain a good transition of concrete strength in elements. The application of graded concrete is the potential to save construction cost up to $50 \%$ due to the reduction of the amount of binder in the concrete mixture. This concrete strength grading aims to concentrate higher concrete 
strength on compressive fibres, while lower concrete strength is placed on the tension side of the element [13-18].

\section{Discussion}

The use of fly ash as a construction material is one of the best solutions to reduce the number of environmental pollutants resulted from a coal-fired power plant in Indonesia. The operation of this power plants ensures the availability of fly ash that will continue to increase over the time. By substituting cement using fly ash on bridge construction, it can indirectly reduce the adverse impact of fly ash waste on the environment and $\mathrm{CO}_{2}$ emissions on cement manufacture processing.

In economic terms, expensive cement prices, especially in remote areas of Indonesia, cause some bridges to be improper. This is because the quality of mixed materials that used is not qualified the standards. The price of fly ash which is more affordable than cement, makes the application of GECOBRIDGE can reduce the cost of construction and produce an economical bridge without reducing the quality of the bridge. The technique of making concrete gradation by concentrating the quality of high streghth concrete only on the top of the concrete beam is also one of the efforts to reduce the cost of construction and make GECOBRIDGE easier when applied in the field. In addition, the innovative design of GECOBRIDGE structure elements make it easier on maintaining the bridge.

Application of GECOBRIDGE on a large scale can encourage equity of the global economy in Indonesia through equitable distribution of sustainable development. If remote areas in Indonesia already have adequate infrastructure of roads and bridges, there will be an increasing quality of the community's economy in Indonesia. The concept of water harvesting on GECOBRIDGE can also be used to irrigate hydroponic plants in green houses around the bridge. In addition, after the water in the storage tanks through the filtration and distillation process, water can be used as a water supply for fish ponds near the green house. So that with this system will be realized an insight environment hamlet which is integrative and solutive to the existing problems.

\section{References}

1. R. Kannankutty and D.J. Flemming, in Bridg. Eng. (2000), p. 10.

2. AASHTO, AASHTO LRFD Bridge Design Specifications, Customary U.S. Units (2012).

3. D. Eyl, Porous Asph. 1 (2003).

4. WAPA, Wisconsin Asph. Pavement Assoc. 1 (2015).

5. AASHTO, AASHTO Guide for Design of Pavement Structures (1993).

6. B.J. Allred, U. Ars, and S. Drainage, in Symp. Appl. Geophys. to Eng. Environ. Probl. 2010 (2008), pp. 190-202.

7. M.U.D. Ahmad, W.G.M. Bastiaanssen, and R.A. Feddes, Irrig. Drain. 51, 227 (2002).

8. Sciences (New. York). 9, 10 (1969).

9. T.J. Van Dam, Concr. Pavement Technol. Progr. 1 (2010).

10. J.J. Triwulan, Ekaputri, in World Coal Ash Conf. (2011).

11. P. Risdanareni, J.J. Ekaputri, and Triwulan, Mater. Sci. Forum 803, 125 (2014).

12. P. Risdanareni, J.J. Ekaputri, and M.M.A.B. Abdullah, Appl. Mech. Mater. 754-755, 406 (2015).

13. M.I.A. Aleem and P.. Arumairaj, Int. J. Eng. Sci. Emerg. Technol. 1, 118 (2012).

14. H. Aylie, B.S. Gan, S. As'ad, and M.M.A. Pratama, Int. J. Eng. Technol. Innov. 5, 233 (2015). 
15. M. Mirza Abdillah Pratama, H. Aylie, B. Sthenly Gan, B. Sri Umniati, P. Risdanareni, and S. Fauziyah, AIP Conf. Proc. 1887, (2017).

A. Hidayat, J. Puspowardojo, and F. Abdul, Procedia Eng. 125, 1023 (2015).

16. B.S. Gan, H. Aylie, and M.M.A. Pratama, in Procedia Eng. (2015), pp. 885-891.

17. Sulistyana, Purwanto, V. Widoanindyawatib, and M.M.A. Pratama, in Procedia Eng. (2014), pp. 465-472.

18. Han, B.S. Gan, and M.M.A. Pratama, Int. J. Technol. 7, 732 (2016). 